\title{
Self-Diffusion Coefficients, Aggregation Numbers and the Range of Existence of Spherical Micelles of Oxyethylated Alkylphenols
}

\author{
Victor P. Arkhipov ${ }^{1} \cdot$ Natalia A. Kuzina ${ }^{1} \cdot$ Andrei Filippov $^{2,3}$ (D)
}

Received: 7 December 2020 / Revised: 12 March 2021 / Accepted: 16 March 2021 /

Published online: 25 March 2021

(c) The Author(s) 2021

\begin{abstract}
Aggregation numbers were calculated based on measurements of the self-diffusion coefficients, the effective hydrodynamic radii of micelles and aggregates of oxyethylated alkylphenols in aqueous solutions. On the assumption that the radii of spherical micelles are equal to the lengths of fully extended neonol molecules, the limiting values of aggregation numbers corresponding to spherically shaped neonol micelles were calculated. The concentration and temperature ranges under which spherical micelles of neonols are formed were determined.
\end{abstract}

\section{Introduction}

Changes in the size and shape of supramolecular structures are observed in solutions of surfactants at varied concentrations, temperatures, and in the presence of organic or inorganic salts and co-surfactants [1]. When the surfactant concentration of the solution is less than the critical micelle concentration, $C<\mathrm{CMC}$, the solution is true, molecular and the surfactant persists in the monomeric state. At $C>>\mathrm{CMC}$, micelles are formed, the size and shape change with increasing surfactant concentration in the solution from spherical to spherocylindrical and more complex shapes are formed [2-4]. At surfactant concentrations slightly exceeding the CMC, a transitional premicellar formation takes place, in which surfactant molecules combine into dimers, trimers and tetramers [5]. As the surfactant concentration increases, the degree of aggregation also increases, and stable (on the microscopic scale) micelles are formed within the lifetimes of surfactant molecules in the micelles, $\sim 10^{-6} \mathrm{~s}$. At

Andrei Filippov

Andrei.Filippov@1tu.se

1 Department of Physics, Kazan National Research Technological University, 420015 Kazan, Russian Federation

2 Chemistry of Interfaces, Luleå University of Technology, 97187 Luleå, Sweden

3 Kazan State Medical University, 420012 Kazan, Russian Federation 
$C>\mathrm{CMC}$, a nonionic surfactant solution is a mixture of monomers, dimers, trimers $\ldots$ and micelles with a polydisperse size and shape distribution $[6,7]$.

Aqueous solutions of nonionic surfactants [8] have another particular property-the phenomenon of turbidity is observed under certain conditions, as a result of changes of the solubility of nonionic surfactants in water, both as a result of an increase in temperature and as a result of changes in the properties of the solvent (water), the introduction of salts, alcohols with salting out, or, conversely, salting in $[9,10]$. The phenomenon of turbidity is explained by dehydration of the oxyethylene fragments of nonionic surfactant molecules, which are responsible for the solubility of the nonionic surfactants in water, and the formation of dehydrated aggregates from nonionic surfactant molecules released into a separate phase of the solutionthe phase enriched with nonionic surfactant molecules and, accordingly, depleted in water. With an increase in the size of the aggregates, up to sizes on the order of $10^{2} \mathrm{~nm}$, the solution becomes turbid due to incoherent light scattering. The method of extraction at cloud point (CPE) is based on the phase separation and different solubility of impurities in the enriched and depleted surfactant phases [11, 12]. A simple and environmentally friendly CPE method is used for the extraction of organic impurities [13], metal and ions [14], the concentration of analytes [15], and wastewater treatment [16].

Figure 1 schematically shows the evolution of micelles and aggregates of nonionic surfactants in aqueous solutions with a change in concentration and temperature from the monomeric aqueous to the aggregated dehydrated state.

With a change in the size and shape of micelles [17, 18], the aggregation numbers (the number of monomers in a micelle) change from several tens in spherical micelles to several hundreds and thousands in rod-like, ellipsoidal micelles and dehydrated aggregates. $\mathrm{CMC} 2$, the surfactant concentration corresponding to the transition from spherical to rod-like micelles [19-21], initiates a change in the physicochemical properties of the solution and, in particular, the aggregation numbers.

To select the optimal CPE conditions, it is necessary to study the aggregation properties of nonionic surfactant solutions. The established methods for studying the structural, dynamic, and aggregation properties of surfactant solutions are the methods of NMR spectroscopy and NMR diffusomery. The aim of this work was to determine the aggregation numbers of nonionic surfactant molecules in micelles

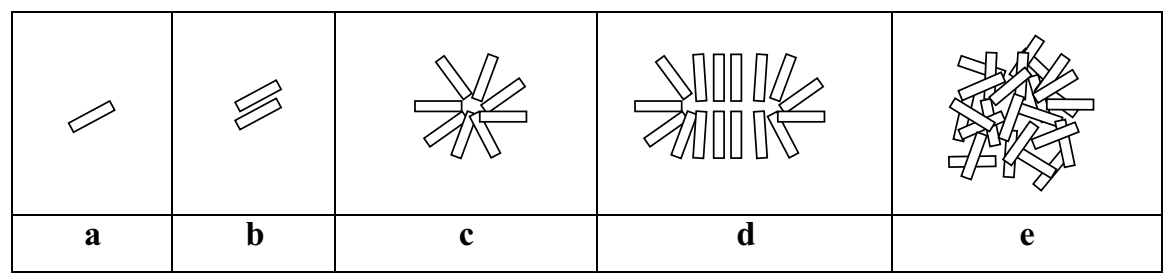

Fig. 1 State of nonionic surfactant molecules in aqueous solutions: a $C<\mathrm{CMC}-$ molecular solution of monomers, b $C<\mathrm{CMC}$-premicellar formation-dimers, trimers appear in the solution, c, d $C<\mathrm{CMC}-$ micellar formation-the shape of the micelles changes from spherical to spherocylindrical, e area of aggregates of dehydrated nonionic surfactant molecules 
and aggregates, starting from monomeric solutions and ending with the region of dehydrated aggregates at the cloud point. The objects of study are oxyethylated alkyl phenols (neonols). To calculate the aggregation numbers, measurements of the selfdiffusion coefficients (SDC) were used [22, 23], on the basis of which the effective radii of micelles and aggregates were determined using the Stokes-Einstein relation and the aggregation numbers were calculated.

\section{Experimental Part}

\subsection{Materials}

In this work, nonionic surfactants, oxyethylated monoalkylphenols (neonols) AF9-n, produced by "Nizhnekamskneftekhim Ltd.," were used [24]. The neonols are a mixture of polyethylene glycol ethers of monoalkylphenols $\mathrm{C}_{9} \mathrm{H}_{19} \mathrm{C}_{6} \mathrm{H}_{4} \mathrm{O}\left(\mathrm{C}_{2} \mathrm{H}_{4} \mathrm{O}\right)_{\mathrm{n}} \mathrm{H}$, where $\mathrm{C}_{9} \mathrm{H}_{19}$ is the alkyl isononyl radical attached to phenol, predominantly in the para position to the hydroxyl group; $n$ is the average number of moles of ethylene oxide attached to one mole of alkylphenols. Oxyethylated monoalkyl phenols are highly effective nonionic surfactants. They are used for water flooding of oil fields for augmentation of oil production, for drilling of wells, in the textile, pulp, and paper, woodworking industries, as a component in lubricating cooling, hydraulic and other process liquids, in ferrous metallurgy, as an active base for technical detergents, feedstock for synthesis of some types of active bases for textile- auxiliary products, and in some other branches of industry. Neonols at $n \leq 6$ are not soluble in water, AF9-8 has limited solubility and AF9-9,10,12 are water-soluble. The main physicochemical characteristics of individual neonols are shown in Table 1. To prepare the solutions, we used deuterated water $\mathrm{D}_{2} \mathrm{O}$ (degree of substitution 99.9\%) to exclude the intense line of water protons from the NMR spectra.

\subsection{NMR Diffusometry}

The self-diffusion coefficients of micelles and neonol aggregates were measured on NMR spectrometers Tesla-BS567A $\left({ }^{1} \mathrm{H}-100 \mathrm{MHz}\right)$ using Hahn's two-pulse sequence [27] and Bruker-Avance $\left({ }^{1} \mathrm{H}-400 \mathrm{MHz}\right)$ using stimulated spin echo [28] with pulsed magnetic field gradient. The amplitude of the spin-echo signal is given by:

Table 1 Physicochemical characteristics of individual neonols

\begin{tabular}{lllll}
\hline Neonol & AF9-8 & AF9-9 & AF9-10 & AF9-12 \\
\hline M, g/mol & 573 & 617 & 661 & 749 \\
Density, g/cm ${ }^{3}[24]$ & $1.062 \pm 0.003$ at & $1.045 \pm 0.003$ & $1.040 \pm 0.003$ at & $1.046 \pm 0.003$ at \\
& $20{ }^{\circ} \mathrm{C}$ & at $40{ }^{\circ} \mathrm{C}$ & $50{ }^{\circ} \mathrm{C}$ & $50{ }^{\circ} \mathrm{C}$ \\
Cloud point, ${ }^{\circ} \mathrm{C}[24]$ & $32 \pm 3$ & $54 \pm 3$ & $66 \pm 3$ & $86 \pm 3$ \\
CMC, mM & $0.0794[25]$ & - & $0.082[25,26]$ & $0.100[25]$ \\
\hline
\end{tabular}




$$
A=A_{0} \exp \left(-\gamma^{2} \delta^{2} g^{2} D t_{d}\right),
$$

where $\gamma$ is the hyromagnetic ratio of protons; $\delta$ and $g$ are duration and amplitude of pulsed magnetic field gradient, respectively; $t_{d}$ is the diffusion time; and $D$ is the self-diffusion coefficient. In the measurements, the magnitude of the pulse gradient was a variable parameter, $t_{d}=50 \mathrm{~ms}$, the number of scans $\mathrm{NS}=4$. repetition time $\mathrm{RT}=5 \mathrm{~s}$.

Figure 2 shows the NMR spectrum of AF9-9 neonol. The spectra of other neonols are similar, only the intensity of the line of protons of oxyethylene differs. In the entire range of temperatures and concentrations, the Lorentzian shape of the lines is preserved, which corresponds to the high mobility of molecules and micelles of neonols. The observed self-diffusion coefficients, Tables 1 and 2, are in the range of $10^{-10}-10^{-11} \mathrm{~m}^{2} / \mathrm{s}$.

The self-diffusion coefficients were measured from the diffusion decays of the integral intensities of oxyethylene protons. All diffusion decays-the dependences of $\ln (\mathrm{I})$ on the parameters of the pulsed gradient-were linear (single-exponential) for all neonols in the entire range of changes in the characteristics of solutions: temperature and concentration. Typical diffusion decays of the echo signal are shown in Fig. 3.

In general, a nonionic surfactant solution is a mixture of monomers, dimers, micelles and, when approaching cloudiness conditions, aggregates of partially or

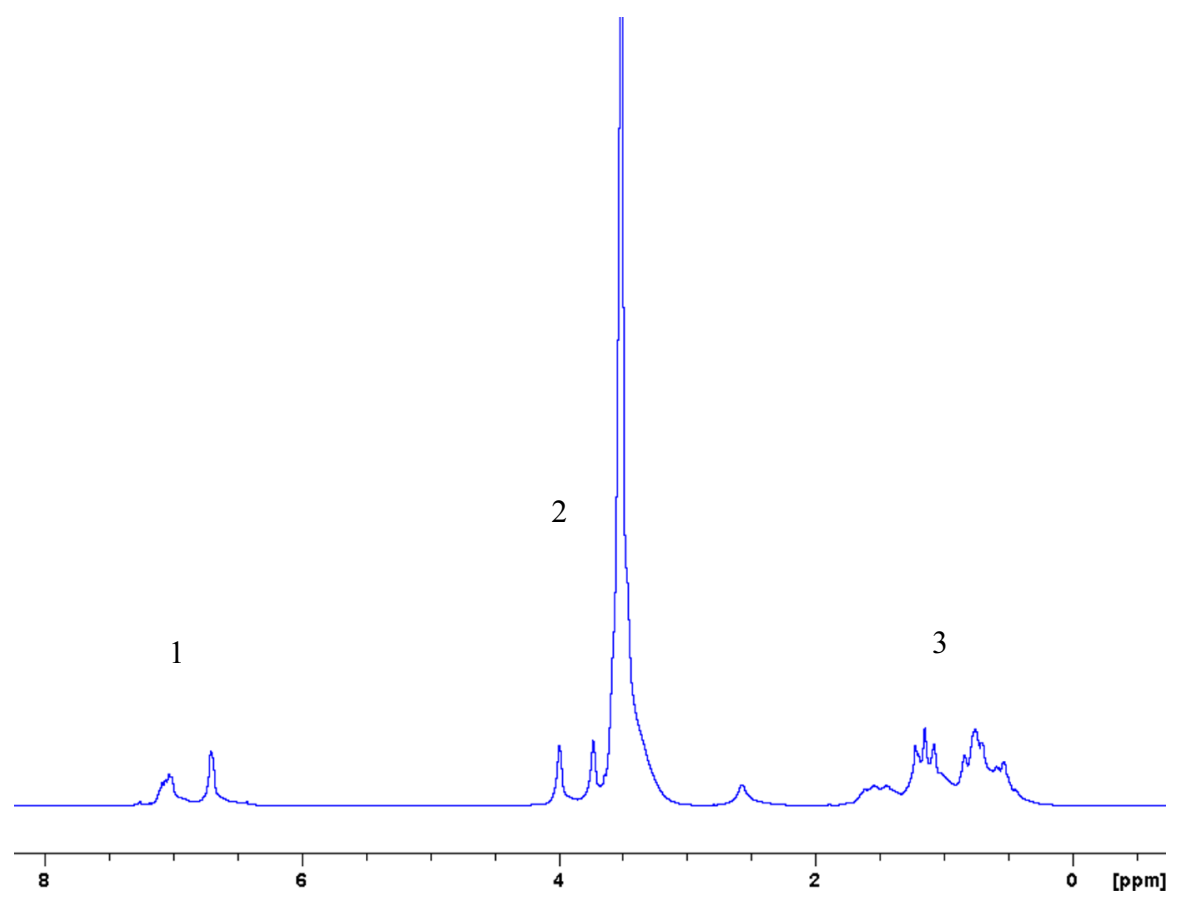

Fig. $2{ }^{1} \mathrm{H}(400 \mathrm{MHz}) \mathrm{NMR}$ spectrum of neonol AF9-9 in $\mathrm{CDCl}_{3}$ at $C=1 \mathrm{wt} \%, t=25{ }^{\circ} \mathrm{C}: \mathbf{1}$ group of lines of phenylene protons, $\mathbf{2}$ group of lines of oxyethylene protons, $\mathbf{3}$ group of lines of alkyl protons 
Table 2 Self-diffusion coefficients [22] and effective hydrodynamic radii of micelles depending on the concentration of neonols in aqueous $\left(\mathrm{D}_{2} \mathrm{O}\right)$ solutions at $25^{\circ} \mathrm{C}$

\begin{tabular}{lllllllllc}
\hline Surfactant & $C, \mathrm{mM}$ & 0.78 & 1.56 & 3.12 & 6.25 & 12.5 & 25 & 50 & 100 \\
\hline AF9-8 & $D 10^{11}, \mathrm{~m}^{2} / \mathrm{s}$ & 8.6 & 8.15 & 3.47 & 2.48 & 1.63 & 1.02 & 0.465 & 0.217 \\
& $R, \mathrm{~nm}$ & 2.23 & 2.35 & 5.51 & 7.68 & 11.60 & 18.27 & 38.90 & 78.29 \\
AF9-9 & $D 10^{11}, \mathrm{~m}^{2} / \mathrm{s}$ & 9.7 & 9.12 & 6.09 & 5.25 & 4.12 & 3.43 & 2.65 & 1.42 \\
& $R, \mathrm{~nm}$ & 1.98 & 2.10 & 3.14 & 3.63 & 4.59 & 5.42 & 6.79 & 11.85 \\
AF9-10 & $D 10^{11}, \mathrm{~m}^{2} / \mathrm{s}$ & 10.3 & 9.7 & 7.5 & 7.26 & 6.22 & 5.55 & 4.4 & 3.15 \\
& $R, \mathrm{~nm}$ & 1.86 & 1.97 & 2.55 & 2.62 & 3.03 & 3.34 & $4.11^{*}$ & $5.38^{* *}$ \\
AF9-12 & $D 10^{11}, \mathrm{~m}^{2} / \mathrm{s}$ & 12 & 11.3 & 8.5 & 8.04 & 7.83 & 7.3 & 5.97 & 4.52 \\
& $R, \mathrm{~nm}$ & 1.60 & 1.69 & 2.25 & 2.36 & 2.40 & 2.53 & 2.97 & 3.61 \\
\hline
\end{tabular}

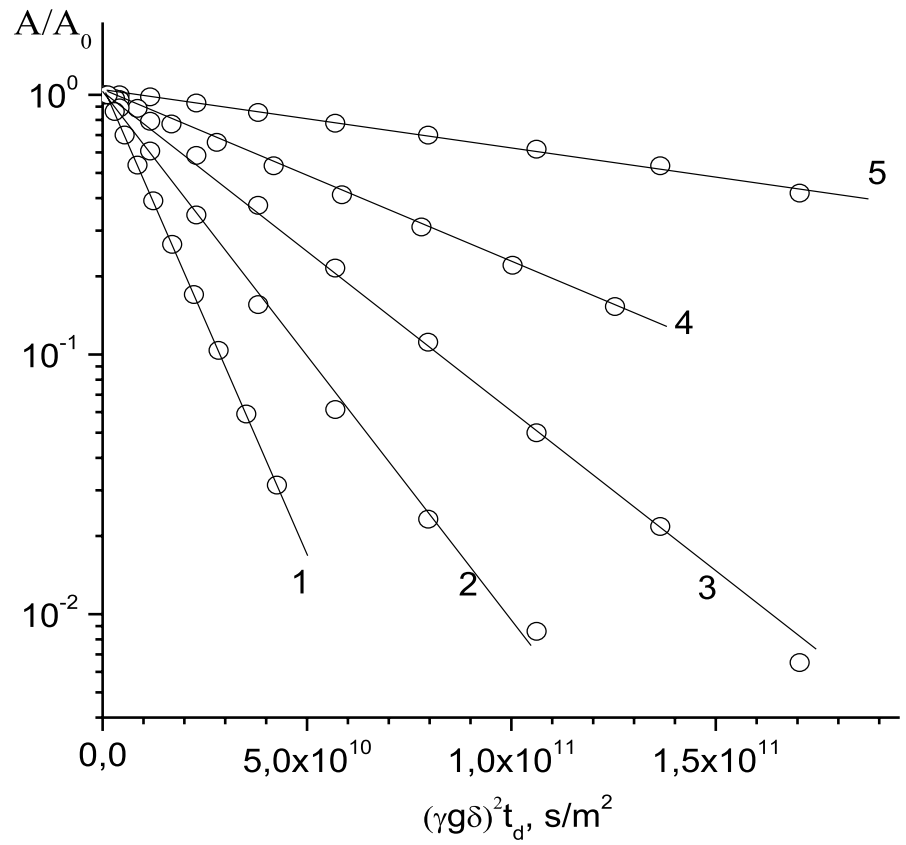

Fig. 3 Diffusion decays of the spin-echo signal in aqueous solutions of neonols: 1 AF9-12 at $75{ }^{\circ} \mathrm{C} ; 2$ AF9- 10 at $20{ }^{\circ} \mathrm{C} ; \mathbf{3}, 4$ AF9-9 at 25 and $55^{\circ} \mathrm{C} ; \mathbf{5}$ AF9-8 at $30^{\circ} \mathrm{C}$ at $C=1$ wt. $\%$

completely dehydrated molecules. The measured SDC represent a weighted average value considering the distribution of nonionic surfactant molecules over these states. Calculation of the diffusion coefficients of micelles or aggregates is usually performed within the framework of the model of two states of nonionic surfactants in solution-monomeric and micellar with concentrations: $C_{\text {mon }}=\mathrm{CMC}$, $C_{\text {mic }}=\mathrm{C}-\mathrm{CMC}$, respectively. Then the measured SDC is expressed by a simple relation [29]: 


$$
D=\frac{D_{\mathrm{mon}} \cdot \mathrm{CMC}+D_{\mathrm{mic}} \cdot(C-\mathrm{CMC})}{C},
$$

where $D_{\text {mon }}$ and $D_{\text {mic }}$ are self-diffusion coefficients of monomers and micelles, and $C$ is the concentration of the surfactant. The contribution of the micellar state increases with an increase in the surfactant concentration, and at $C>1 \mathrm{wt} \%$, the contribution of the monomeric state can be neglected, and the measured SDC is assumed to be equal to the SDC of the micelles [30, 31].

We considered, within the framework of the two-state model, two mechanisms of translational motion of surfactant molecules corresponding to the monomeric and micellar forms of neonols in solution.

\subsection{Radii of Micelles}

Based on experimental data $[22,23]$ of the SDC of the neonols, the effective hydrodynamic radii of micelles and aggregates were calculated using the Stokes-Einstein relation:

$$
R=\frac{k T}{\alpha \pi \eta D_{0}}
$$

where $k$ is the Boltzmann constant, $\mathrm{T}$ is the absolute temperature, $\eta$ is the dynamic viscosity, and $D_{0}$ is the SDC at infinite dissolution. The coefficient $\alpha$ depends on boundary conditions for the particle-medium; $\alpha=4$ for so-called sliding conditions, and $\alpha=6$ for adhesive conditions [32,33]. Hydrogen bonds of water molecules with the oxygen of oxyethylene groups provide adhesive conditions; therefore, in calculating the radii of micelles and aggregates, we used the value $\alpha=6$. For calculating $D_{0}$ relation [34] was used, which takes into account the effect of the hydrodynamic interaction of micelles:

$$
D=D_{0}(1-2 \phi)
$$

where $D$ and $\phi$ are the experimental values of the SDC and the volume fraction of micelles or aggregates in the solution, respectively.

It should be noted that in the calculations of the micelle radii and aggregation numbers performed below, we used the effective hydrodynamic radii (2) in the approximation of the spherical shape of diffusing particles (micelles or aggregates).

\subsection{Aggregation Numbers}

The aggregation number, the number of nonionic surfactant molecules in a micelle, was determined by comparing the micelle mass, $M$, with the mass of the neonol molecules, $m$. The micelle mass was calculated from the values of the effective hydrodynamic radii and the density of neonols, Table 1.

$$
N_{\text {agg }}=\frac{M}{m},
$$


the mass of micelles in the approximation of their spherical shape is related to the density of the neonols, $\rho$, and the volume of a micelle by the ratio:

$$
M=\rho \cdot V_{\text {mic }}=\rho \cdot \frac{4}{3} \pi R_{\text {mic }}^{3} .
$$

\section{Results and Discussion}

The values of SDC of neonols AF9-8, AF9-9, AF9-10 and AF9-12 in aqueous $\left(\mathrm{D}_{2} \mathrm{O}\right)$ solutions, calculated using the Stokes-Einstein ratio, and taking into account corrections for the interaction of micelles in the approximation of their spherical shape, the values of the effective hydrodynamic radii of micelles of neonols are presented in Tables 2 and 3.

With increasing concentration of neonols in solutions, the SDC decrease, and the hydrodynamic radii of micelles increase. In addition, the SDC values decrease, and the micelle radii increase with a decrease in the number of oxyethylene groups in the neonol molecules, the hydrogen bonds of which interact with water molecules to ensure the solubility of neonols in water.

With increasing temperature, the increase in the intensity of thermal movement, along with the increase in the size of the neonol micelles caused by their dehydration lead to the overall effect of an atypical decrease in SDC with temperature in solutions of neonols AF9-8, AF9-9 and AF9-10. The hydrodynamic radii of micelles in solutions of all neonols increase with temperature.

Figures 4 and 5 show the dependences of the aggregation numbers of neonols in $\mathrm{D}_{2} \mathrm{O}$ solutions depending on their concentrations and temperatures, calculated by Eqs. $(5,6)$ using the micelle radii from Tables 2 and 3 in the approximation of the spherical shape of micelles.

Calculations were based on the assumption that micelles are spherical. The shape of micelles of ionic surfactants with increasing concentration changes from spherical to ellipsoidal, spherocylindrical, worm-like, up to the formation of liquid crystal structures [2]. Micelles of non-ionic surfactants have a characteristic feature, which

Table 3 Self-diffusion coefficients [23] and effective hydrodynamic radii of micelles of neonols in aqueous $\left(\mathrm{D}_{2} \mathrm{O}\right)$ solutions depending on temperature at $C=1 \mathrm{wt} \%$

\begin{tabular}{llllllll}
\hline Surfactant & $t,{ }^{\circ} \mathrm{C}$ & 30 & 40 & 52 & 62 & 73 & 83 \\
\hline AF9-8 & $D 10^{11}, \mathrm{~m}^{2} / \mathrm{s}$ & 1.14 & 0.695 & & & & \\
& $R, \mathrm{~nm}$ & 18.8 & 35.1 & & & & \\
AF9-9 & $D 10^{11}, \mathrm{~m}^{2} / \mathrm{s}$ & 2.38 & 1.95 & 1.85 & & & \\
& $R, \mathrm{~nm}$ & 8.78 & 14.45 & 19.73 & & & \\
AF9-10 & $D 10^{11}, \mathrm{~m}^{2} / \mathrm{s}$ & 6.50 & 6.05 & 5.48 & 4.80 & & \\
& $R, \mathrm{~nm}$ & 3.30 & 4.71 & 6.59 & 9.26 & & \\
AF9-12 & $D 10^{11}, \mathrm{~m}^{2} / \mathrm{s}$ & 8.83 & 10.7 & 12.4 & 13.4 & 13.1 & 11.9 \\
& $R, \mathrm{~nm}$ & 2.43 & 2.66 & 2.92 & 3.30 & 4.09 & 5.34 \\
\hline
\end{tabular}

SDC in solutions of AF9-10 were measured at concentrations: *_44 mM, **_80 $\mathrm{mM}$ 


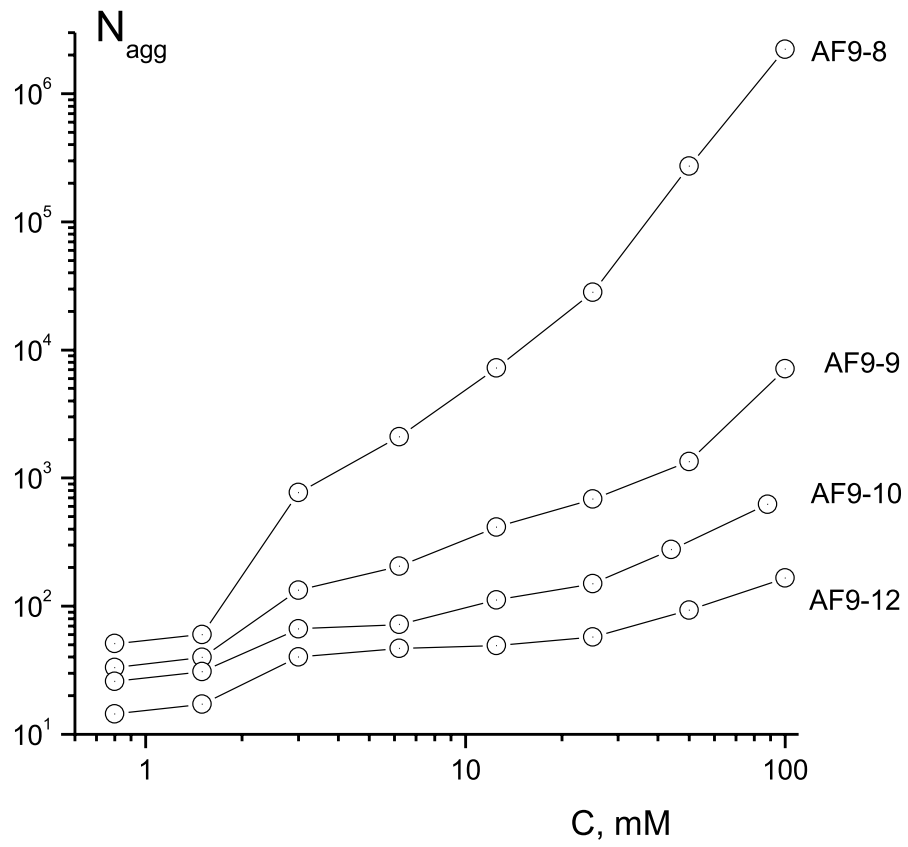

Fig. 4 Aggregation numbers depending on the concentration of neonols in aqueous $\left(\mathrm{D}_{2} \mathrm{O}\right)$ solutions at $25^{\circ} \mathrm{C}$

distinguishes them from ionic surfactants, associated with the destruction of hydrogen bonds with temperature and the formation of aggregates from dehydrated molecules $[2,9]$. The aggregation numbers increase sharply with a decrease in the number of oxyethylene groups in neonol molecules, that is, with a decrease in the degree of solubility of neonols in water. A decrease in solubility leads to an increase in the size of micelles and aggregates. The sharp increase in the size and aggregation numbers when approaching turbidity conditions is explained by the complete loss of solubility and the formation of aggregates from dehydrated nonionic surfactant molecules.

Below we describe how we calculated the limiting values of aggregation numbers for spherical micelles, assuming the micelle radius $\mathrm{R}$ is equal to the length 1 of fully extended neonol molecules [22]. Spherical micelles or Gartley micelles have an internal part of intertwining hydrocarbon radicals and an external part formed by polar groups of surfactant molecules turned into the aqueous phase. The diameter of such micelles is twice the length of surfactant molecules [1-3]. The calculations were performed in two ways: (1) comparing micelle masses with the masses of neonol molecules, and (2) comparing the volumes of micelles with the volumes of individual molecules. The volumes and masses of the micelles were calculated from the effective hydrodynamic radii and density of the neonols, Table 1; to calculate the volumes of the molecules, we used the method of atomic increments [33, 35].

In the first way, we calculated the aggregation numbers by comparing the masses of micelles and individual neonol molecules: 


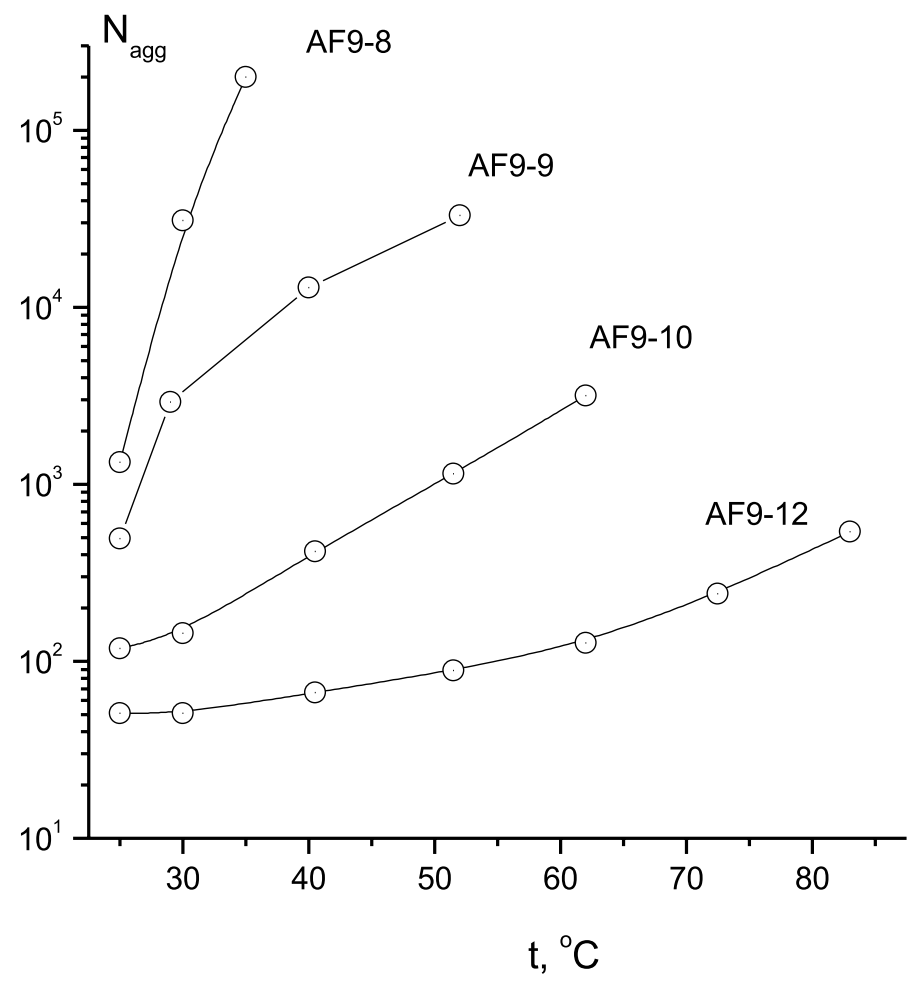

Fig. 5 Aggregation numbers of neonols in aqueous $\left(\mathrm{D}_{2} \mathrm{O}\right)$ solutions depending on the temperature at $C=1 \mathrm{wt} \%$

$$
N_{\mathrm{agg}}^{\max }=\frac{\rho \frac{4}{3} \pi l^{3}}{m},
$$

where $\rho$ and $m$ are the density and mass of the neonol molecules, respectively, Table 1. The mass of a molecule is:

$$
m=\mu / N_{A},
$$

where $M$ is the molar mass of the neonol and $N_{A}$ is Avogadro's number.

The calculations show that the maximum aggregation numbers for spherical micelles are 320, 390, 470, 620 for the neonols AF9-8, AF9-9, AF9-10 and AF9-12, respectively.

In the second way, we calculated the volumes, $\mathrm{v}$, of neonol molecules by the method of atomic increments, using the values of the volumes of atoms [33], and calculated the values of the aggregation numbers:

$$
N_{\text {agg }}^{\max }=\frac{\frac{4}{3} \pi l^{3}}{v} \cdot f
$$


where $f$ is the packing coefficient, the value of which for a simple cubic lattice is nearly 0.52 , for a face-centered cubic lattice is 0.68 and for a hexagonal lattice has a maximum value of 0.74 . Taking the packing coefficient of molecules in micelles as equal to some average value of 0.65 , we calculated the limiting values of the aggregation numbers to be $340,420,510,670$ inspherical micelles of neonols AF9-8, AF9-9, AF9-10 and AF9-12, respectively.

As can be seen from Figs. 4 and 5, the aggregation numbers for the micelles of neonol AF9-12 do not exceed the maximum possible for spherical micelles value, therefore, in the entire investigated range of temperatures and concentrations, micelles of neonol AF9-12 retained their spherical shape.

Micelles of neonol AF9-10 have a spherical shape at a temperature of $25{ }^{\circ} \mathrm{C}$ throughout the studied concentration range up to $C=100 \mathrm{mM}$, while the aggregation numbers remain lower than the maximum possible for spherical micelles value $N_{\text {agg }}<490$. At the same time, at temperatures above $40{ }^{\circ} \mathrm{C}$, the aggregation numbers exceed the maximum possible value for spherical micelles of this neonol, which indicates the formation, for example, of spherocylindrical micelles or the beginning of the dehydration process.

Micelles of neonol AF9-9 at a temperature of $25{ }^{\circ} \mathrm{C}$ have a spherical shape at concentrations of $C<10 \mathrm{mM}$, while the values of the aggregation numbers are less than the maximum values for micelles of the spherical shape of neonol AF99. At a concentration of $1 \mathrm{wt} \%(16 \mathrm{mM})$ and temperatures from $25{ }^{\circ} \mathrm{C}$ and higher, micelles of neonol AF9-9 can no longer be spherical, the aggregation numbers exceed those of neonol AF9-9.

Micelles of neonol AF9-8 at a temperature of $25{ }^{\circ} \mathrm{C}$ have a spherical shape at concentrations $C<2 \mathrm{mM}$, while the values of the aggregation numbers are less than the maximum values for spherical micelles of neonol AF9-8. At a concentration of $1 \mathrm{wt} \%(17.5 \mathrm{mM})$ and temperatures from $25{ }^{\circ} \mathrm{C}$ and higher, micelles of neonol AF9-8 can no longer be spherical, the aggregation numbers exceed those of neonol AF9-8.

\section{Conclusions}

Based on the measurements of the self-diffusion coefficients of neonols AF9-8, AF9-9, AF9-10 and AF9-12 in aqueous solutions, the values of the aggregation numbers in micelles were calculated. On the assumption that the radii of spherical micelles are equal to the lengths of fully extended neonol molecules, the limiting values of aggregation numbers corresponding to the spherical shape of neonol micelles were calculated. In this study, we have established the concentration and temperature ranges in which spherical micelles of neonols exist.

Acknowledgements We thank Scriptia Academic Editing for English correction and proofreading of this manuscript.

Funding Open access funding provided by Lulea University of Technology. 
Open Access This article is licensed under a Creative Commons Attribution 4.0 International License, which permits use, sharing, adaptation, distribution and reproduction in any medium or format, as long as you give appropriate credit to the original author(s) and the source, provide a link to the Creative Commons licence, and indicate if changes were made. The images or other third party material in this article are included in the article's Creative Commons licence, unless indicated otherwise in a credit line to the material. If material is not included in the article's Creative Commons licence and your intended use is not permitted by statutory regulation or exceeds the permitted use, you will need to obtain permission directly from the copyright holder. To view a copy of this licence, visit http://creativecommons.org/ licenses/by/4.0/.

\section{References}

1. K. Shinoda, T. Nakagawa, B.-I. Tamamushi, T. Isemura, Colloidal Surfactants. Some Physicochemical Properties (Academic Press, New York, 1963), p. 320

2. M.J. Schick, Micellization, solubilization, and microemulsions, in Plenum. ed. by K.L. Mittal (Springer, New York, 1977), pp. 487-945

3. C. Tanford, J. Phys. Chem. 76(21), 3020-3024 (1972)

4. D.I.D. Eini, B.W. Barry, C.T. Rhodes, J. Colloid Interface Sci. 54(3), 348-351 (1976)

5. R. Hadgiivanova, H. Diamant, J. Phys. Chem. B 111(30), 8854-8859 (2007)

6. P. Mukerjee, J. Phys. Chem. 76(4), 565-570 (1972)

7. D.G. Hall, Langmuir 15(10), 3483-3485 (1999)

8. R. Dong, J. Hao, Chem. Rev. 110(9), 4978-5022 (2010)

9. P. Mukherjee, S.K. Padhan, S. Dash, S. Patel, B.K. Mishra, Adv. Colloid Interface Sci. 162(1-2), 59-79 (2011)

10. J.-L. Li, D.-S. Bai, B.-H. Chen, Colloids Surf. A 346(1-3), 237-243 (2009)

11. W.L. Hinze, E. Pramauro, Crit. Rev. Anal. Chem. 24, 133-177 (1993)

12. E.K. Paleologos, D.L. Giokas, M.I. Karayannis, TrAC, Trends Anal. Chem. 24(5), 426-436 (2005)

13. S. Akita, H. Takeuchi, Sep. Sci. Technol. 30(5), 833-846 (1995)

14. C.B. Ojeda, F.S. Rojas, Anal. Bioanal. Chem. 394(3), 759-782 (2009)

15. S. Xie, M.C. Paau, C.F. Li, D. Xiao, M.M. Choi, J. Chromatogr. A 1217(16), 2306-2317 (2010)

16. P. Trakultamupatam, J.F. Scamehorn, S. Osuwan, Sep. Sci. Technol. 37(6), 1291-1305 (2002)

17. M. Velinova, D. Sengupta, A.V. Tadjer, S.J. Marrink, Langmuir 27(23), 14071-14077 (2011)

18. P.H. Nelson, G.C. Rutledge, T.A. Hatton, J. Chem. Phys. 107(24), 10777-10781 (1997)

19. S. May, A. Ben-Shaul, J. Phys. Chem. B 105(3), 630-640 (2001)

20. L.M. Bergström, Curr. Opin. Colloid Interface Sci. 22, 46-50 (2016)

21. F.M. Kuni, A.K. Shchekin, A.I. Rusanov, A.P. Grinin, Colloid J. 66(2), 174-185 (2004)

22. V.P. Arkhipov, E.F. Potapova, O.N. Antzutkin, A. Filippov, Magn. Reson. Chem. 51(7), 424-430 (2013)

23. V.P. Arkhipov, ZSh. Idiyatullin, E.F. Potapova, O.N. Antzutkin, A. Filippov, J. Phys. Chem. B 118(20), 5480-5487 (2014)

24. Nizhnekamskneftekhim Ltd. Neonols. Specifications. Detailed Tables (2018) https://elarum.ru/info/ standards/tu-2483-077-05766801-98/. Accessed 28 Nov 2018

25. I.S. Razina, Ph.D. Thesis, KNRTU, Kazan, Russia (2009)

26. A. Tihova, N. Gluhareva, A. Kolesnikova, Sci. Bull. BelSU Ser. Nat. Sci. 21, 127-131 (2010)

27. E. Hahn, Phys. Rev. 80(4), 580-594 (1950)

28. J.E. Tanner, J. Chem. Phys. 52(5), 2523-2526 (1970)

29. M. Jansson, P. Stilbs, J. Phys. Chem. 89(22), 4868-4873 (1985)

30. E. Sutherland, S.M. Mercer, M. Everist, D.G. Leais, J. Chem. Eng. Data 54(1), 272-278 (2009)

31. A.I. Rusanov, T.G. Movchan, E.V. Plotnikova, Colloid J. 79(5), 661-667 (2017)

32. J.R. Schmidt, J.L. Skinner, J. Chem. Phys. 119(15), 8062-8068 (2003)

33. J.T. Edward, J. Chem. Educ. 47(4), 261-270 (1970)

34. H.N.W. Lekkerkerker, J.K.G. Dhont, J. Chem. Phys. 80(11), 5790-5792 (1984)

35. A.V. Bondi, J. Phys. Chem. 68(3), 441-451 (1964)

Publisher's Note Springer Nature remains neutral with regard to jurisdictional claims in published maps and institutional affiliations. 